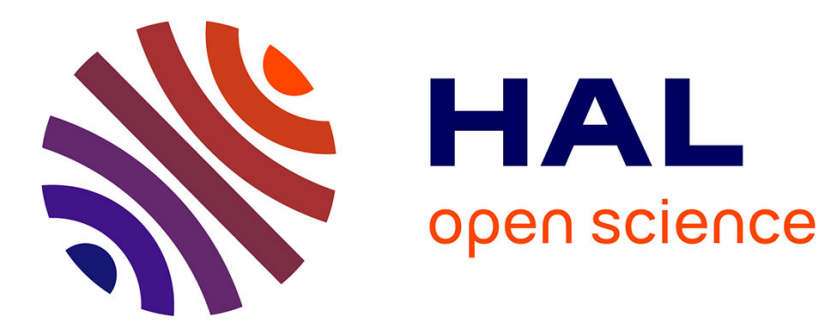

\title{
First-principles study of boron speciation in calcite and aragonite
}

Etienne Balan, Fabio Pietrucci, Christel Gervais, Marc Blanchard, Jacques

Schott, Jérome Gaillardet

\section{To cite this version:}

Etienne Balan, Fabio Pietrucci, Christel Gervais, Marc Blanchard, Jacques Schott, et al.. Firstprinciples study of boron speciation in calcite and aragonite. Geochimica et Cosmochimica Acta, 2016, 193, pp.119-131. 10.1016/j.gca.2016.07.026 . hal-01371923

\section{HAL Id: hal-01371923 \\ https://hal.sorbonne-universite.fr/hal-01371923}

Submitted on 26 Sep 2016

HAL is a multi-disciplinary open access archive for the deposit and dissemination of scientific research documents, whether they are published or not. The documents may come from teaching and research institutions in France or abroad, or from public or private research centers.
L'archive ouverte pluridisciplinaire HAL, est destinée au dépôt et à la diffusion de documents scientifiques de niveau recherche, publiés ou non, émanant des établissements d'enseignement et de recherche français ou étrangers, des laboratoires publics ou privés. 
Revision 1

Etienne Balana, ${ }^{\mathrm{a},}$, Fabio Pietruccia, Christel Gervais ${ }^{\mathrm{b}}$, Marc Blancharda, $^{\mathrm{a}}$

Jacques Schottc , Jérome Gaillardet ${ }^{d}$

aSorbonne Universités - Institut de Minéralogie, de Physique des Matériaux et de Cosmochimie (IMPMC), UPMC Université Paris 06, UMR CNRS 7590, UMR IRD 206, MNHN, 4 place Jussieu, 75252 Paris cedex 05, France bSorbonne Universités - Laboratoire de Chimie de la Matière Condensée de Paris (LCMCP), UPMC Université Paris 06, UMR CNRS 7574, 4 place Jussieu, 75252 Paris cedex 05, France

cGéosciences Environnement Toulouse, Observatoire Midi-Pyrénées, CNRSDiderot, CNRS, F-75005 Paris, France, and Institut Universitaire de France.

${ }^{*}$ Corresponding author: Prof. Etienne Balan, Institut de Minéralogie, Physique des Matériaux et Cosmochimie, Case 115, 4 Place Jussieu, 75252 Paris Cedex 05.

tel: $\quad 00.33 .1 .44 .27 .74 .52$ fax: 00.33 .1 .44 .27 .37 .85 E-mail:

Etienne.Balan@impmc.upmc.fr 
Despite the importance of boron as a proxy of past ocean $\mathrm{pH}$, the crystal-chemical factors controlling its incorporation in the structure of calcium carbonates are still poorly understood. This is partly linked to an imperfect knowledge of the coordination, protonation state and local environment of boron species in these minerals. In the present study, we use first-principles quantum mechanical tools to model selected trigonal and tetragonal boron species in calcite and aragonite. The stable geometry of the models is obtained from standard energy minimization schemes or using a more advanced metadynamics exploration of their configurational space. The computation of ${ }^{11} \mathrm{~B}$ NMR chemical shifts and quadrupolar coupling parameters enables a straightforward comparison of the models to existing experimental NMR data. The results show that $\mathrm{B}$ in calcium carbonates does occur as structural species substituted for $\mathrm{CO}_{3}{ }^{2-}$ anions. The $\mathrm{B}$ speciation depends on the polymorph considered. In calcite, structural boron is present as partially deprotonated trigonal $\mathrm{BO}_{2}(\mathrm{OH})^{2-}$ species coexisting with a fraction of substituted $\mathrm{B}(\mathrm{OH})_{4}^{-}$groups. In aragonite, the $\mathrm{B}(\mathrm{OH})_{4}^{-}$ substitution for $\mathrm{CO}_{3}{ }^{2-}$ anions is dominant. Different species, including entrapped $\mathrm{B}(\mathrm{OH})_{3}$ molecules and substituted $\mathrm{BO}_{3}{ }^{3-}$ groups also occur in biogenic samples. The diversity of B speciation reflects a diversity of B incorporation mechanisms and sheds light on previous studies confronting $B$ isotopic composition determination with NMR observations. The mechanisms of boron incorporation in calcium carbonates are probably more complex than usually assumed in the literature using boron isotopes as a proxy of paleo-atmospheric $\mathrm{CO}_{2}$ reconstructions. Although not invalidating the empirical paleo-pH proxy, these results call for a better understanding of the fundamental mechanisms of boron incorporation in carbonates. 


\section{INTRODUCTION}

53

54

55

56

57

The isotopic composition of boron in biogenic calcite and aragonite has been proposed and successfully used as a proxy of the past ocean acidity, which in turn reflects past levels of atmospheric $\mathrm{CO}_{2}$ concentrations (Vengosh et al. 1991; Hemming and Hanson 1992). A large number of studies have applied this idea to various biogenic carbonates, proposed paleo- $\mathrm{CO}_{2}$ secular evolutions for the Earth's atmosphere and established the sensitivity of global climate to atmospheric $\mathrm{CO}_{2}$ in the past (e.g., Spivack et al. 1993; Gaillardet and Allègre 1995; Sanyal et al. 1995; Palmer et al. 1998; Pearson and Palmer 1999; Lemarchand et al. 2002; Pagani et al. 2005; Pearson et al. 2009; Martinez-Boti et al. 2015). The use of boron isotopes as a paleo-pH meter is based on the large difference in ${ }^{11} \mathrm{~B} /{ }^{10} \mathrm{~B}$ ratio $(27.2 \%$ in delta notation of isotopic abundances; Klochko et al. 2006) occurring between the major dissolved forms of boron, the trigonal boric acid $\left(\mathrm{B}(\mathrm{OH})_{3}\right.$, preferentially enriched in $\left.{ }^{11} \mathrm{~B}\right)$, and the tetragonal borate ion $\left(\mathrm{B}(\mathrm{OH})_{4}^{-}\right.$, preferentially enriched in $\left.{ }^{10} \mathrm{~B}\right)$, under thermodynamic equilibrium conditions (Zeebe 2005; Liu and Tossell 2005; Klochko et al. 2006; Rustad et al. 2010; Nir et al. 2015). As the relative proportion of these aqueous species is strongly $\mathrm{pH}$-dependent in the range of expected seawater $\mathrm{pH}$, mass balance considerations require that their isotopic composition is also pH-dependent. Assuming that among the two major B species present in seawater only the borate ion $\left(\mathrm{B}(\mathrm{OH})_{4}^{-}\right)$is incorporated in the mineral structure during crystal growth and that no boron isotope fractionation occurs during uptake, the $\mathrm{B}$ isotopic composition in marine carbonate samples provides a straightforward record of the secular variations of seawater $\mathrm{pH}$.

The assumption of sole $\mathrm{B}(\mathrm{OH})_{4^{-}}$incorporation is challenged by spectroscopic studies reporting various proportions of both trigonal and tetragonal B species 
coexisting in calcite and aragonite samples. Both boron partitioning and speciation are polymorph dependent, aragonite incorporating tetragonal boron more easily than calcite (e.g. Sen et al. 1994; Branson et al. 2015; Mavromatis et al. 2015). Direct determination of the boron coordination state can be achieved using ${ }^{11} \mathrm{~B}$ solid-state nuclear magnetic resonance (NMR) (Sen et al. 1994; Klochko et al. 2006; Rollion-Bard et al. 2011; Mavromatis et al. 2015), electron energy loss spectroscopy (EELS) (RollionBard et al. 2001) and scanning transmission X-ray microscopy (STXM) (Branson et al. 2015). The observation of an often dominant contribution of trigonal B in calcite, and its occurrence in aragonite, has been interpreted as reflecting a coordination change of borate ions at the surface of growing crystals (Hemming et al. 1998; Klochko et al. 2009; Branson et al. 2015). This interpretation is consistent with in-situ Atomic Force Microscopy (AFM) observations of the morphology and dynamic of the surface of calcite crystals growing from B-bearing solutions (Ruiz-Agudo et al. 2012). According to this mechanism, the boron isotopic composition in the mineral phase still reflects that of the borate ions in the solution. This explains the success of the boron-isotope proxy for paleo-pH reconstitutions from mineral remains of extinct species. However, several studies have suggested that a fraction of incorporated B could correspond to boric acid molecules, directly scavenged from the solution (Xiao et al. 2008, Rollion-Bard et al. 2011, Noireaux et al. 2015). Consistently, higher than expected ${ }^{11} \mathrm{~B} /{ }^{10} \mathrm{~B}$ ratio have been determined on inorganically precipitated and biogenic calcium carbonate samples. Isotopic effects in biogenic carbonates have also been shown to depend upon the calcifying species. Although local variations of $\mathrm{pH}$ at the calcification site can surely contribute to the isotopic variability observed in biologically produced calcium carbonates, inorganic precipitation experiments under well-constrained pH conditions 
101

102

cannot be reconciled with models based on the exclusive incorporation of borate ions, showing that the basis hypotheses of the paleo-pH theory are questionable.

Despite the importance of the boron-isotope $\mathrm{pH}$ proxy, the crystal-chemical factors controlling boron incorporation in carbonates are still elusive. Several factors impede a detailed understanding of its incorporation mechanisms. Differences between the geometry of the stiff molecular tetragonal B anions and that of the trigonal substitution sites can lead to substantial modifications of the medium-range structure around the B species. Various electrostatic charge compensation mechanisms (e.g. involving different protonation states, presence of vacancies, or incorporation of other trace elements) can also affect the B environment, which significantly increases the system complexity. These effects are difficult to determine from experiment because spectroscopic methods usually provide information restricted to the well-defined first coordination shell of boron. Complementary to experimental observations, theoretical approaches can bring important constraints to discuss molecular-scale aspects of B incorporation in calcium carbonates. Tossell $(2005,2006)$ has investigated the NMR spectroscopic and the thermodynamic properties of boron species using molecular modeling techniques. Although these studies mostly focused on B species in aqueous solutions and did not treat explicitly the role of the crystalline matrix, they provided quantitative relations between the geometry and protonation state of the boron complexes and their distinctive NMR parameters. In the light of the experimental data of Sen et al. (1994), Tossell (2005) suggested that the incorporation of trigonal B should occur via a distorted, partially deprotonated group instead of more symmetric fully protonated or deprotonated groups. Tossell (2006) and Klochko et al. (2009) also suggested that chemically more complex species such as $\mathrm{B}(\mathrm{OH})_{2} \mathrm{CO}_{3}{ }^{-}$could account for the experimental observations of Sen et al. (1994). 
127 determine the most favorable coordination states and geometry of boron species in

128 calcite and aragonite and discuss related incorporation mechanisms. We theoretically

129 determine the stable configuration of atomic-scale models of boron in calcium

130 carbonates, using an approach similar to that previously developed to study sulfate

131 incorporation in carbonates (Balan et al. 2014). The computation of the related NMR

132 parameters (Pickard and Mauri 2001; Charpentier 2011; Bonhomme et al. 2012) then

133 enables a straightforward comparison of the theoretical models to existing NMR

134 experimental data. The results attest to the diversity of B speciation in synthetic and

135 biogenic calcium carbonates; among which the substitution of partially protonated

136 trigonal $\mathrm{BO}_{2}(\mathrm{OH})^{2-}$ and fully protonated tetragonal $\mathrm{B}(\mathrm{OH})_{4}^{-}$groups for $\mathrm{CO}_{3}{ }^{2-}$ anions are 137 dominant.

\section{METHODS}

2.1 Structural optimization of models of boron-bearing calcium carbonates

143

First-principles quantum mechanical calculations provide the electronic density and total energy of a system made of nuclei and electrons by solving the corresponding Schrödinger equation. Many properties of a system (e.g. equilibrium structure, elastic

147 constants, vibrational modes, ...) are in fact determined by the total energy and its

148 variations. These methods are considered as highly predictive because their ingredients

149 are not fitted on experimental data. All of them are however characterized by a trade-off between computation time and accuracy. In the past twenty years, methods based on 
151 the density functional theory (DFT) have reached a level of accuracy high enough to 152 reproduce with an excellent agreement the static and dynamic properties of 153 geochemically relevant systems (see, e.g., Cygan and Kubicki 2001). The present 154 calculations were performed within the DFT framework, using periodic boundary 155 conditions and the generalized gradient approximation (GGA) to the exchange156 correlation functional as proposed by Perdew, Burke and Ernzerhof (PBE; Perdew et al.

157 1996). The ionic cores were described by ultra-soft pseudopotentials from the GBRV 158 library (Garrity et al. 2014); which means that only the electrons contributing to 159 chemical bonding are explicitly treated, while those occupying the core states are 160 considered to be unaffected by variations in the atom environment. The electronic 161 wave-functions and charge density were expanded using a finite basis sets of plane162 waves with 40 and 200 Ry cutoffs, respectively, corresponding to a convergence of the 163 total energy better than $1 \mathrm{mRy} /$ atom.

164 Periodic models of boron-bearing calcium carbonates were built for the two 165 common $\mathrm{CaCO}_{3}$ polymorphs: calcite $(R \overline{3} c, 10$ atoms per rhombohedral primitive cell) 166 and aragonite (Pmcm, 20 atoms per primitive cell). In order to minimize as much as 167 possible spurious interactions between the periodic images of the boron defects, the 168 unit-cell of the models was built from the $2 \times 2 \times 2$ super-cells of calcite (rhombohedral 169 cell, 80 atoms) and aragonite (160 atoms) previously used in Balan et al. (2014). The 170 equilibrium geometry of these models was obtained by displacing the atoms up to a 171 minimum energy state, characterized by the fact that the forces experienced by the 172 atoms vanish. These structure relaxations were done using the PWscf code of the 173 Quantum ESPRESSO package (Giannozzi et al. 2009; http://www.quantum174 espresso.org) and forces on atoms were minimized to less than $10^{-4}$ Ry/a.u. The 
175 Brillouin zone sampling was restricted to a single $k$-point; which is appropriate to treat 176 such systems with large unit-cell.

177 A reference theoretical sassolite (boric acid; $\mathrm{B}(\mathrm{OH})_{3}$ ) structure was obtained 178 using a $2 \times 2 \times 2 k$-points grid. The relaxed cell volume $\left(\mathrm{V}=285.28 \AA^{3}\right)$ and bond lengths $179(\mathrm{~d}(\mathrm{~B}-\mathrm{O})=1.378 \AA \mathrm{A} ; \mathrm{d}(\mathrm{O}-\mathrm{H})=1.01 \AA$ ) slightly overestimate their experimental 180 counterparts $\left(V=273.62 \AA^{3} ; d(B-0)=1.36 \AA ̊ d(O-H)=0.9 \AA ̊\right.$; Zachariasen 1954), which 181 is consistent with a previous DFT-GGA modeling study (Ferlat et al. 2006). A theoretical 182 structure of takedaite $\left(\mathrm{Ca}_{3} \mathrm{~B}_{2} \mathrm{O}_{6}\right)$ was also obtained with a $2 \times 2 \times 2 k$-points grid, leading to 183 relaxed cell volume $\left(\mathrm{V}=785.23 \AA^{3}\right)$ and bond lengths $(\mathrm{d}(\mathrm{B}-0)=1.391 \AA$ ) slightly larger 184 than experimental values $\left(V=765.61 \AA^{3}, \mathrm{~d}(\mathrm{~B}-\mathrm{O})=1.384 \AA ̊ \AA\right.$; Vegas et al. 1975).

\subsection{First-principles metadynamics} determine the most stable configuration of $\mathrm{B}(\mathrm{OH})^{-}$in its crystal host from an exploration of the free-energy landscape drawn by variations in the H-bonding pattern.

191 This approach provides an efficient method to explore a free-energy landscape potentially displaying several relative minima separated by barriers higher than the relevant thermal energy. Usual molecular dynamics would require prohibitively high temperature and/or long simulation to achieve an adequate sampling of the corresponding phase space. In contrast, the metadynamics builds an history dependent

196 bias potential which drives the system away from the previously explored 197 configurations, thus accelerating the exploration of the phase space and providing an 198 elegant way to pass the energy barriers. In practice, the bias potential is built in a space 199 of reduced dimensionality depending on the properties under study and referred to as 
collective variables space. For example, a chemical reaction can be described by 201 selecting a specific inter-atomic distance reflecting the breaking or the formation of a 202 chemical bond. In the present study, exploring the different possible configurations of a 203 given tetragonal boron group with respect to the calcite/aragonite crystal host equates 204 to exploring different topologies in the network of chemical interactions formed by covalent and hydrogen bonds in a boron-centered region.

Born-Oppenheimer metadynamics runs were performed in the NVT ensemble (i.e. the number of atoms, volume and average temperature were constant during the runs) using the same DFT framework and parameters as those used for the structural relaxations. The hydrogen mass was increased to two atomic mass units and the runs 210 were carried out with a timestep of $0.4 \times 10^{-15} \mathrm{~s}$. Temperature was controlled to $300 \mathrm{~K}$ employing a stochastic velocity rescaling thermostat (Bussi et al. 2007). Both in aragonite and calcite, we employed SPRINT collective variables (Pietrucci and Andreoni 2011), as implemented in Plumed (Bonomi et al., 2009), including a total of 26 atoms, namely the 4 hydrogens belonging to $\mathrm{B}(\mathrm{OH})_{4}^{-}$and 22 oxygens belonging to carbonates and lying within $4 \AA$ of the oxygens belonging to $\mathrm{B}(\mathrm{OH})_{4}$. The 26 collective variables were biased simultaneously adding every 100 molecular dynamics steps Gaussian hills of height $5.2 \mathrm{~kJ} / \mathrm{mol}$ and width 0.9 or 1.1 (for aragonite or calcite, respectively).

To facilitate the identification of the different metastable configurations explored along the metadynamics trajectory, we performed a structural cluster analysis in the space of SPRINT collective variables, employing the k-medoids algorithm as

221 implemented in the software piv-clustering (Gallet and Pietrucci 2013). 
226 Zeeman effect and the interaction of the nuclear quadrupolar moment with the electric 227 field gradient at the nucleus. Accordingly, three parameters can be extracted from ${ }^{11} \mathrm{~B}$ 228 NMR spectra, namely the chemical shift $\delta_{\text {iso, }}$, the quadrupolar coupling constant $C_{Q}$ and the asymmetry parameter $\eta$.

The NMR chemical shift describes the difference between the applied external magnetic field and the magnetic field at the nucleus positions. It can be obtained from

232 the structural models by calculating the shielding of the nuclei relative to the electronic 233 current induced by the external magnetic field. This current was calculated by using the GIPAW approach, which allows reconstructing the all-electron magnetic response from the pseudo-wave-functions (Pickard and Mauri 2001; Charpentier 2011; Bonhomme et al. 2012). The calculations were performed using the PWscf and GIPAW codes of the Quantum ESPRESSO package (Giannozzi et al. 2009). Norm-conserving pseudopotentials were used and the wave functions kinetic energy cutoff was increased to 80 Ry. The integral over the Brillouin zone was done using a Monkhorst-Pack $1 \times 1 \times 1 k$ point grid for the different models and $2 \times 2 \times 2$ for sassolite $\left(\mathrm{B}(\mathrm{OH})_{3}\right)$ used as a reference.

241 The isotropic chemical shift $\delta_{\text {iso }}$ is defined as $\delta_{\text {iso }}=-\left(\sigma-\sigma^{\text {ref }}\right)$, where $\sigma$ is the isotropic 242 shielding (one-third of the trace of the NMR shielding tensor) and $\sigma^{\text {ref }}$ is the isotropic 243 shielding of the same nucleus in a reference system. In our calculations, absolute 244 shielding tensors are obtained. To fix the scales, $\sigma^{\text {ref }}$ was chosen by comparing 245 experimental (19.2 ppm, Soraru et al. 1999) and calculated $\delta_{\text {iso }}$ values in $\mathrm{B}(\mathrm{OH})_{3}$. The $C_{Q}$ and $\eta$ parameters are related to the eigenvalues of the electric field 247 gradient tensor and reflect the symmetry of the $\mathrm{B}$ environment. The $\mathrm{C}_{\mathrm{Q}}=2.49 \mathrm{MHz}$ and $248 \eta=0.0$ parameters computed for sassolite $\left(\mathrm{B}(\mathrm{OH})_{3}\right)$ are consistent with experimental 
values (2.47 $\mathrm{MHz}$ and 0.0; Klochko et al. 2009). It should be noted that for the $\mathrm{C}_{\mathrm{Q}}\left({ }^{11} \mathrm{~B}\right)$

250 calculation, a quadrupole moment of $35 \mathrm{mb}$ was used: this value is smaller than the 251 theoretical value of $40 \mathrm{mb}$ (Pyykkö, 2008) as recommended by Soleilhavoup et al. 252 (2010) in borosilicate glasses. Estimated precision is $\pm 0.5 \mathrm{ppm}, \pm 0.1 \mathrm{MHz}$ and \pm 0.1 for $253 \delta_{\text {iso, }} \mathrm{C}_{\mathrm{Q}}$ and $\eta$, respectively.

\section{RESULTS}

\subsection{Trigonal boron incorporation at the carbonate site}

We first consider the incorporation of trigonal boron species. The simplest model 260 is obtained by substituting a $\mathrm{B}^{3+}$ for a $\mathrm{C}^{4+}$ (Table 1$)$. The charge balance is obtained by spreading homogeneously an electrostatic counter-charge over the unit-cell. The crystal site symmetry is preserved. The three equivalent B-O bonds in calcite have a length of $1.388 \AA$ A. The $\mathrm{BO}_{3}{ }^{3-}$ group in aragonite displays a mirror symmetry with a shorter B-O distance of $1.380 \AA$ on the mirror plane and two symmetric B-O distances of $1.383 \AA$. The high symmetry of $\mathrm{BO}_{3}{ }^{3-}$ groups in the homogeneously compensated models leads to very small $\eta$ parameters. Compared to calcite, the aragonite ${ }^{11} \mathrm{~B}$ chemical shift is higher and similar to that of the calcium orthoborate, takedaite.

A more realistic charge compensation mechanism consists in adding one $\mathrm{H}$ atom 269 to the previous system, forming a $\mathrm{BO}_{2}(\mathrm{OH})^{2-}$ group (Fig. 1). For the 3-fold calcite site, the 270 three oxygen atoms are symmetrically equivalent and only one protonation scheme was considered. Two different protonation schemes are considered for aragonite, affecting 272 the oxygen on the mirror plane of the $\mathrm{BO}_{3}$ triangle (scheme $\mathrm{A}$ ) or one of the other two 273 symmetric oxygen atoms (scheme B). Scheme A is more stable than B by $16.8 \mathrm{~kJ} / \mathrm{mol}$ 
274 and should be thermodynamically dominant at room temperature. The $\mathrm{BO}_{2}(\mathrm{OH})^{2-}$ 275 species in calcite and aragonite display similar structural characteristics. The OH group 276 points out of the $\mathrm{BO}_{3}$ triangle sharing a $\mathrm{H}$-bond of moderate strength with an oxygen 277 belonging to an adjacent carbonate group. A significant distortion of the trigonal 278 geometry is observed with the $\mathrm{B}-\mathrm{O}(\mathrm{H})$ distance increasing by $\sim 0.1 \AA \AA$; whereas the two 279 other B-O distances decrease by 0.03 to $0.04 \AA$. Compared to the models with an 280 homogeneous charge compensation, the ${ }^{11} \mathrm{~B} \delta_{\text {iso }}$ decreases by 1.5 and by 3 to 4 ppm in 281 calcite and aragonite, respectively; whereas the quadrupolar coupling parameter $\mathrm{C}_{\mathrm{Q}}$ is 282 weakly affected. The asymmetry parameter $\eta$ increases to 0.8 indicating a strong departure from the revolution symmetry, consistent with the in-plane distortion of the $\mathrm{BO}_{3}$ triangle.

285

\subsection{Tetragonal boron incorporation at the carbonate site}

Following an approach similar to that applied to the trigonal B species, $\mathrm{B}(\mathrm{OH})_{4}^{-}$ for $\mathrm{CO}_{3}{ }^{2-}$ substitution was modeled by using a homogeneous electrostatic background to compensate the charge imbalance. Previous calculations on sulfate incorporation in carbonate (Balan et al. 2014) provided a suitable starting guess for the structural optimization. However, the large number of potential H-bond acceptors around the impurity increases the probability to drive the system to a metastable configuration.

294 This difficulty was circumvented by performing first-principles metadynamics (FPM) 295 runs (Laio and Parrinello 2002; Pietrucci and Andreoni 2011) to explore the free energy landscape of the borate group conformation and to isolate the most favorable one. The aragonite FPM run lasted $\sim 6 \times 10^{-12} \mathrm{~s}$ (Fig. 2, video file in electronic annex). 
zero and less than $10 \mathrm{~kJ} / \mathrm{mol}$, indicating that different configurations are being explored 300 (zero bias corresponds to an unexplored region of the configuration space). In a second 301 phase, the bias potential starts to grow more consistently to few tens of $\mathrm{kJ} / \mathrm{mol}$ without 302 coming back to zero. This indicates that the available low-energy configurations have 303 been exhausted and that higher-energy configurations have been explored. 304 Concomitantly, the fluctuations of the SPRINT topological variables related to $\mathrm{H}$ and $\mathrm{O}$ 305 atoms (Fig. 2) attest to the changes of configuration of the $\mathrm{B}(\mathrm{OH})_{4}^{-}$species, by 306 reorienting the $\mathrm{OH}$ groups to engage in different patterns of hydrogen bonds with the 307 carbonates. The trajectory analysis leads to 8 maximally distinct instantaneous 308 configurations. After structural optimization, two classes of configurations differing by 309 the orientation of the $03-\mathrm{H}$ bond (almost parallel to the b-axis or to the c-axis), could be 310 defined. In the following, only the most stable configuration will be considered since the energy difference between the two $(19 \mathrm{~kJ} / \mathrm{mol})$ is significantly larger than the typical 312 thermal energy at ambient temperature $(2.5 \mathrm{~kJ} / \mathrm{mol})$. In this configuration (Fig. 1), the 313 O3-H bond is almost parallel to the c-axis and the borate group is slightly distorted with 314 an average B-0 length of $1.481 \AA$ (Table 1). As for sulfate (Balan et al. 2014), the borate 315 group is tilted with respect to the $(a, b)$ plane and a significant displacement of the 316 neighboring carbonate groups is observed. The four $\mathrm{H}$-bonds display quite regular 317 characteristics with $\mathrm{O}-\mathrm{H}$ distances ranging from 0.989 to $1.008 \AA$ and $\mathrm{O}(\mathrm{H}) \ldots \mathrm{O}$ distances 318 from 2.62 to $2.65 \AA$ A. Few relative energy minima were however observed in each 319 configuration class due to moderate displacements of the surrounding carbonates, 320 leading to energy differences ranging between 5 and $13 \mathrm{~kJ} / \mathrm{mol}$. These configurations 321 can be envisioned as intermediate states in the transition from one H-bonding geometry 322 to the other. A longer FPM run (15 x $10^{-12}$ s, Fig. 3, video file in electronic annex $)$ was 323 performed on calcite but only two different instantaneous configurations were 
identified, leading to a single relaxed structure. As observed for other tetrahedral anions in calcite (Reeder et al. 1994; Fernandez-Diaz et al. 2010; Balan et al. 2014), the B(OH) $4^{-}$ anion is slightly tilted with the apical B-O bond forming an angle of $13^{\circ}$ with respect to

327 the ternary axis of calcite. Although the structural environment is different, only slight 328 differences in the B-O and H-bond distances are observed between calcite and aragonite 329 (Table 1). The theoretical ${ }^{11} \mathrm{~B}$ NMR parameters of $\mathrm{B}(\mathrm{OH})_{4}^{-}$in calcite and aragonite are 330 similar, with $\delta_{\text {iso }}$ close to $1 \mathrm{ppm}$ and small quadrupolar coupling parameters (Table 1 ). As for the trigonal B species, alternative models of tetragonal borate in calcium 332 carbonates were explored by assuming local charge compensation mechanisms. 333 Removing a proton from the $\mathrm{B}(\mathrm{OH})_{4}^{-}$group, modifies its charge to -2 (equivalent to that 334 of the $\mathrm{CO}_{3}{ }^{2-}$ group). Starting from the tetrahedral geometries obtained from FPM runs, 335 four relaxed schemes (matching the four different $\mathrm{H}$ atoms of the borate group) are obtained for each calcium carbonate polymorph. The deprotonation of the 03-H group (Table 1) is favored in aragonite by more than $27 \mathrm{~kJ} / \mathrm{mol}$. In calcite, the most stable (by more than $7 \mathrm{~kJ} / \mathrm{mol}$ ) configuration is obtained by deprotonation of the $02-\mathrm{H}$ group 339 (Table 1). All the $\mathrm{BO}(\mathrm{OH})_{3}{ }^{2-}$ species display a significant distortion of the boron 340 coordination shell. Consistently, the $C_{Q}$ values increase, ranging between 1.01 and 1.53 MHz.

A different mechanism ensuring the neutrality of $\mathrm{B}(\mathrm{OH})_{4}^{-}$for $\mathrm{CO}_{3}{ }^{2-}$ substitution corresponds to the coupled substitution of a monovalent cation for $\mathrm{Ca}^{2+}$. Sodium is the 344 most relevant one both in terms of seawater abundance and ionic radii similarity. Two 345 configurations have been selected by assuming that the $\mathrm{Na}^{+}$for $\mathrm{Ca}^{2+}$ substitution affects 346 the site closest to the central boron atom (Fig. 1). In both configurations, the structure of 347 the $\mathrm{B}(\mathrm{OH})_{4^{-}}$group and the H-bonding pattern is weakly affected by the $\mathrm{Na}^{+}$for $\mathrm{Ca}^{2+}$ 348 substitution. The Na to B distances increase by $\sim 0.05 \AA ̊$ compared to Ca to B distances. 
349 Compared with the homogeneously compensated models, only weak variations of the 350 11B NMR parameters are observed (Table 1).

4. DISCUSSION

353

\subsection{Boron in calcium carbonates: Comparing theory and experiment}

\subsubsection{Trigonal boron speciation}

Although only few studies report experimentally determined NMR parameters of boron in calcite and aragonite, they reveal a significant variability of the trigonal boron environment (Table 2, Fig. 4). The chemical shift of trigonal boron ranges from $16 \mathrm{ppm}$ (calcite) to $22 \mathrm{ppm}$ (heated aragonite) and strong differences are observed on the rhombic $\eta$ parameter. The trigonal boron species in the calcite samples investigated by

363 Sen et al. (1994) is rhombically distorted, with $\eta$ values of 0.67 and 0.5 in the synthetic and biogenic sample, respectively. In contrast, the nil $\eta$ values reported by Klochko et al. (2009) in biogenic calcite and aragonite samples correspond to a radially symmetric environment of boron. A similarly low value of $\eta$ is reported by Rollion-Bard et al.

367 (2011) for a biogenic aragonitic coral sample. As already highlighted by Klochko et al. 368 (2009), these variations in $\eta$ values are highly significant because $\eta$ is only defined between 0 and 1 .

The theoretical parameters determined for the $\mathrm{BO}_{2}(\mathrm{OH})^{2-}$ species in calcite are 371 consistent with those reported by Sen et al. (1994) for synthetic calcite. The chemical 372 shift and quadrupolar coupling of $\mathrm{BO}_{2}(\mathrm{OH})^{2-}$ in aragonite also match the experimental 373 values reported by Mavromatis et al. (2015) for synthetic aragonite. Unfortunately, the $\eta$ 
374 parameter was not reported for this sample, likely because of its low trigonal B content. 375 From the comparison of theoretical and experimental NMR parameters, singly 376 protonated $\mathrm{BO}_{2}(\mathrm{OH})^{2-}$ groups appear as the dominant speciation of trigonal boron in the 377 synthetic calcium carbonates precipitated from solutions. This confirms the previous 378 suggestions that trigonal boron in carbonates should be distorted and partially 379 deprotonated (Hemming and Hanson 1992; Tossell 2005). This speciation is favored by 380 the electrostatic balance requirements. An overall preference for local electrostatic 381 charge compensation in minerals is attested by the observation of chemically complex 382 defects, associating different trace elements in the same crystal site. For example, 383 clumped-defects associating fluoride ions with carbonate groups have been observed in 384 apatite (Yi et al. 2013). Note however that, in absence of $C_{Q}$ and $\eta$ values, some 385 uncertainty affects the interpretation of the NMR parameters reported by Mavromatis et al. (2015) for synthetic calcite samples. Their chemical shift is only slightly lower than 387 that of $\mathrm{BO}_{2}(\mathrm{OH})^{2-}$ species and consistent with the value reported by Sen et al. (1994) for 388 a synthetic calcite sample (Fig. 4). Isotopic compositions (Noireaux et al. 2015) indicate 389 (under the assumption that no isotope fractionation occurs during incorporation) that 390 between $20 \%$ and $40 \%$ of boron in these samples results from the incorporation of 391 aqueous boric acid and that this proportion is linearly correlated with the $\mathrm{pH}$-dependent 392 amount of boric acid in solution. The proportion of trigonal B detected by NMR is 393 however higher than that inferred from isotopic composition (Noireaux et al., 2015). 394 Thus, both borate anions and boric acid molecules could contribute to the incorporation 395 of $\mathrm{BO}_{2}(\mathrm{OH})^{2-}$ species in the bulk of calcite particles. This implies a coordination change 396 of tetragonal borate as well as several deprotonation steps affecting the tetragonal and 397 trigonal boron species in the interfacial region of growing calcite crystals. 

et al. (1994) displays NMR parameters consistent with $\mathrm{BO}_{2}(\mathrm{OH})^{2-}$ groups. In contrast, 400 the parameters reported by Klochko et al. (2009) for a foram calcite correspond to fully 401 deprotonated $\mathrm{BO}_{3}{ }^{3-}$ groups substituted in the calcite structure (Fig. 4, Table 1). The 402 sensitivity of ${ }^{11} \mathrm{~B}$ NMR to the trigonal boron protonation state is further confirmed by 403 the higher $\delta_{\text {iso, }}$ and weak $\eta$, indicative of a more symmetric boron environment in a 404 calcite sample produced by the high-temperature $\left(500^{\circ} \mathrm{C}\right)$ transformation of biogenic aragonite. These parameters are close to those computed for $\mathrm{BO}_{3}{ }^{3-}$ groups in aragonite (Fig. 4) and in the calcium orthoborate takedaite (Table 1). They indicate that the thermally driven aragonite to calcite transformation leads to a full deprotonation of borate groups. They however suggest that the local environment of $\mathrm{BO}_{3}{ }^{3-}$ groups in the heated aragonite differs from that in crystalline calcite. comparatively low $\delta_{\text {iso }}$ value and weak $\eta$ (Klochko et al. 2009; Rollion-Bard et al. 2011).

412 The weak $\eta$ is indicative of a regular coordination shell, but the $\delta_{\text {iso }}$ values are too low to 413 correspond to fully deprotonated $\mathrm{BO}_{3}{ }^{3-}$ groups (Fig. 4; Table 1). Accordingly, these 414 parameters are interpreted as related to fully protonated $\mathrm{B}(\mathrm{OH})_{3}$ molecules. The 415 incorporation of boric acid molecules in crystallographic sites is unrealistic because of 416 the corresponding strong electrostatic charge imbalance. It is more likely that $\mathrm{B}(\mathrm{OH})_{3}$ 417 molecules are directly scavenged from the solution and encapsulated by the solid phase. 418 Such step can involve their incorporation in the amorphous and hydrous calcium 419 carbonate phases, observed under high supersaturation and elevated growth rate 420 conditions and identified as intermediate phases in the growth of biogenic calcium 421 carbonates (e.g. Gower 2008; Purgstaller et al., 2016). The B(OH) $)_{3}$ molecules could also 422 occur in interfacial or porous regions separating ordered $\mathrm{CaCO}_{3}$ nanodomains, such as 
423 those observed in calcitic red coral (Vielzeuf et al. 2008). The preserved coordination

424 state and isotopic composition can lead to higher than expected $\delta^{11} \mathrm{~B}$, depending on the 425 proportion of $\mathrm{B}(\mathrm{OH})_{3}$ molecules relative to the total $\mathrm{B}$ content. This interpretation is 426 consistent with the concomitant observation of elevated $\delta^{11} \mathrm{~B}$ and higher trigonal boron concentration at the center of calcification of an aragonitic coral sample by Rollion-Bard et al. (2011). Note however that trigonal B usually is a minority species in aragonitic samples, which tempers the isotopic effect related to $\mathrm{B}(\mathrm{OH})_{3}$ incorporation.

\subsubsection{Tetragonal boron speciation}

The experimental chemical shift of tetragonal B species displays a range of variation between -2.4 and 3 ppm, considering both calcite and aragonite (Fig. 5). Except two samples with $\delta_{\text {iso }}$ above 2 ppm and two signals with negative chemical shifts ascribed to non-structural species in calcitic samples (Mavromatis et al. 2015), the NMR parameters are consistent with those obtained for the $\mathrm{B}(\mathrm{OH})_{4}^{-}$models. The systematically nil values of experimental quadrupolar coupling parameters (Table 2) attest to a highly symmetric B environment. They rule out the partially deprotonated tetragonal species, which are characterized by theoretical $C_{Q}$ values larger than $1 \mathrm{MHz}$.

441 Accordingly, tetragonal B should mostly occur in the calcium carbonate samples as fully 442 protonated $\mathrm{B}(\mathrm{OH})_{4}^{-}$groups. A high protonation state of tetragonal B was suggested by 443 Klochko et al. (2009) from ${ }^{1} \mathrm{H}$ decoupling experiments. The substitution of $\mathrm{B}(\mathrm{OH})_{4}^{-}$for $\mathrm{CO}_{3}{ }^{2-}$ implies that more remote mechanisms 445 ensure the charge compensation, among which the $\mathrm{Na}^{+}$for $\mathrm{Ca}^{2+}$ substitution is the most 446 probable one. As a matter of fact, the Na-bearing models also display NMR parameters 447 consistent with the experimental observations. This coupled substitution could be 
responsible, at least in part, for the dependence of $\mathrm{B} / \mathrm{Ca}$ ratio on salinity reported for biogenic calcium carbonates (Allen et al. 2011, 2012; Allen and Hönisch 2012; Henehan et al. 2015). Inorganic co-precipitation experiments of Kitano et al. (1978) have also shown a significant increase in B incorporation in calcite with increasing $\mathrm{NaCl}$ concentration in the parent solution. For aragonite, the observed dependence was in the opposite direction but with a comparatively weaker magnitude. We note however that an aragonitic coral sample and an hydrothermal calcitic sample investigated by Klochko et al. (2009) display higher $\delta_{\text {iso }}$ values of 2.54 and $2.87 \mathrm{ppm}$, respectively, and likely correspond to $\mathrm{B}(\mathrm{OH})_{4}^{-}$groups in a different environment or involving a charge compensation mechanism differing from that prevailing in the other samples. The potential presence of contaminant phases cannot be fully excluded for these natural samples. Beside $\mathrm{Na}^{+}$for $\mathrm{Ca}^{2+}$ substitution, different charge compensation mechanisms could occur, as shown by the Na-free synthesis experiments of Hemming et al. (1995) and Sen et al. (1994). For example, $\mathrm{HCO}_{3}{ }^{-}$groups associated with Ca vacancies could play such compensation role. A potential role of phosphate anions substituted for carbonate groups has also been suggested by Henehan et al. (2015). Variations in the borate group environment are also attested by the broad signals with slightly negative chemical shifts observed by Mavromatis et al. (2015), interpreted as corresponding to a fraction of borate groups occurring in defective domains of the calcite samples.

\subsection{Boron speciation in calcium carbonates: Implications for the paleo-pH proxy}

The present results show that B in calcium carbonates does occur as substituted species for $\mathrm{CO}_{3}{ }^{2-}$ anions, thus confirming its structural nature. They further show that its speciation depends on the polymorph considered. This is fully consistent with a number 
473 of previous studies on boron incorporation in biogenic and abiotic carbonates (e.g. 474 Klochko et al. 2009; Mavromatis et al. 2015; Noireaux et al. 2015) and strongly challenge 475 the hypothesis on which the use of boron isotopes to reconstruct paleo ocean $\mathrm{pH}$ has 476 been used (i.e. sole incorporation of the aqueous borate ion). In calcite, structural boron 477 is present as partially deprotonated trigonal $\mathrm{BO}_{2}(\mathrm{OH})^{2-}$ species, coexisting with 478 substituted $\mathrm{B}(\mathrm{OH})_{4}^{-}$groups in a proportion depending on the crystal growth parameters. 479 In aragonite, the $\mathrm{B}(\mathrm{OH})_{4}$ substitution for $\mathrm{CO}_{3}{ }^{2-}$ anions is dominant. The theoretical 480 modeling of NMR spectra also indicates that different B species, including entrapped $481 \mathrm{~B}(\mathrm{OH})_{3}$ molecules and substituted $\mathrm{BO}_{3}{ }^{3-}$ groups can occur in biogenic samples. The 482 diversity of $\mathrm{B}$ speciation indirectly confirms the importance of out-of-equilibrium 483 parameters and interfacial properties in determining the chemical form and abundance 484 of boron in calcium carbonate (e.g., Hemming et al. 1998; Hobbs and Reardon 1999; 485 Ruiz-Agudo et al. 2012; Gabitov et al. 2014; Branson et al. 2015; Noireaux et al. 2015; 486 Uchikawa et al. 2015; Kaczmarek et al. 2016). Although the $\mathrm{B}(\mathrm{OH})_{3}$ molecules in 487 biogenic aragonitic samples might have been directly scavenged from the solution, the 488 other trigonal $\mathrm{BO}_{2}(\mathrm{OH})^{2-}$ and $\mathrm{BO}_{3}{ }^{3-}$ species most probably result from a coordination 489 change and deprotonation of boron species adsorbed at the mineral surface.

490 An important implication of the observed diversity of B speciation in calcium 491 carbonates is that the ratio of trigonal to tetragonal species determined by NMR 492 spectroscopy is not a sufficient parameter to infer its incorporation mechanism. This 493 ratio is not simply related to the trigonal to tetragonal proportion in the solution nor 494 solely results from a coordination decrease affecting the adsorbed borate ion during its 495 incorporation in the crystal structure. The environment and protonation state of 496 trigonal B however appears as more variable than that of the tetragonal species. In this 497 latter case, the variations are most likely related to more remote charge compensation 
mechanisms and do not affect the first coordination shell of boron. In addition, the high sodium concentration of seawater could favor the $\mathrm{Na}^{+}$for $\mathrm{Ca}^{2+}$ substitution in the charge

500 compensation of $\mathrm{B}(\mathrm{OH})_{4}^{-}$species. The prevalence of a specific charge compensation 501 mechanism would reduce the crystal-chemical complexity of the $\mathrm{B}(\mathrm{OH})_{4}$ - incorporation 502 mechanism. Interestingly, the affinity of aragonite is higher than that of calcite for both B 503 and $\mathrm{Na}$. In the case of $\mathrm{Na}$, this has been interpreted as reflecting its incorporation in 504 interstitial sites of calcite, instead of structural Ca site as in aragonite (Ishikawa and 505 Ichikuni 1984; Okumura et al. 1986). As a consequence, aragonitic samples in which 506 tetragonal B is dominant should faithfully reflect the $\mathrm{pH}$ of past oceans, as proposed by 507 Noireaux et al. (2015), provided that sampling strategies taking into account the growth 508 mechanism of biologic aragonite are developed (Rollion-Bard et al. 2011).

509 In the case of calcitic samples, the more diverse boron speciation could be 510 considered as a fingerprint of the growth mechanism and could serve as an indicator to 511 extrapolate the laboratory calibrations to the geologic samples. The recent spatially512 resolved study of Branson et al. (2015) indicates a dominantly trigonal (>85\%) 513 coordination and a heterogeneous distribution of boron in foraminiferal calcite; 514 whereas NMR studies revealed a fraction of tetragonal B in biogenic calcite $(\sim 20 \%$, Sen 515 et al. 1994; 54\%, Klochko et al. 2009). Thus, the occurrence of differently coordinated 516 species, with potentially distinct isotopic compositions, in spatially different domains of 517 the composite biogenic samples cannot be excluded. As diagenesis and alteration may 518 differently affect these domains, the boron isotopic composition of geological samples 519 would then depend on their preservation state (Wara et al. 2003). We note however that 520 the observations of Edgar et al. (2015) suggest that the boron isotopic composition of 521 fossil planktonic foraminiferal calcite is resistant to diagenetic transformations. This 
522 calls for further experimental studies focusing on the effects of diagenesis on boron 523 speciation in carbonates.

524 Finally, we highlight that the approach developed in the present study, which 525 combines a metadynamics determination of stable configurations of polyatomic groups 526 with the first-principles calculation of related spectroscopic parameters, represents a 527 general tool to explore the speciation of molecular anions in host crystalline matrices, 528 readily applicable to a larger range of geochemical proxies in minerals.

529

530

\section{ACKNOWLEDGMENTS}

531

532 This work has been supported by the French National Research Agency through the 533 CARBORIC (ANR-13-BS06-0013-06) project. This work was performed using HPC 534 resources from GENCI-IDRIS (Grants i2016041519 and i2016097535). We thank M. 535 Henehan and two anonymous reviewers for their constructive comments and 536 suggestions. REFERENCES

539 Allen K. A. and Hoenisch B. (2012) The planktic foraminiferal B/Ca proxy for seawater 540 carbonate chemistry: A critical evaluation, Earth Planet. Sci. Lett. 345-348, 20321.

542 Allen K. A., Hoenisch B., Eggins S. M., Yu J., Spero H. J. and Elderfield H. (2011) Controls on boron incorporation in cultured tests of the planktic foraminifer Orbulina universa, Earth Planet. Sci. Lett. 309, 291-30. 
Allen K. A., Hoenisch B., Eggins S. M. and Rosenthal Y. (2012) Environmental controls on $\mathrm{B} / \mathrm{Ca}$ in calcite tests of the tropical planktic foraminifer species Globigerinoides ruber and Globigerinoides sacculifer, Earth Planet. Sci. Lett. 351-352, 270-280,

Balan E., Blanchard M., Pinilla C. and Lazzeri M. (2014) First-principles modeling of sulfate incorporation and ${ }^{34} \mathrm{~S} /{ }^{32} \mathrm{~S}$ isotopic fractionation in different calcium carbonates. Chem. Geol. 374-375, 84-91.

Bonhomme C., Gervais C., Babonneau F., Coelho C., Pourpoint F., Azaïs T., Ashbrook S.E., Griffin J.M., Yates J.R., Mauri F. and Pickard C.I. (2012) First-Principles Calculation of NMR Parameters using the gauge including projector augmented wave method: A chemist's point of view. Chemical reviews 112, 5733-5779.

Bonomi M., Branduardi D., Bussi G., Camilloni C., Provasi D., Raiteri P., Donadio D., Marinelli F., Pietrucci F., Broglia R.A. and Parrinello M. (2009) PLUMED: a portable plugin for free-energy calculations with molecular dynamics. Comp. Phys. Comm. 180, 1961.

Branson O., Kaczmarek K., Refern S. A. T., Misra, S., Langer G., Tyliszczak T., Bijma J. and Elderfield H. (2015) The coordination and distribution of B in foraminiferal calcite. Earth Planet. Sci. Lett. 416, 67-72.

Bussi G., Donadio D. and Parrinello M. (2007) Canonical sampling through velocity rescaling. J. Chem. Phys. 126, 014101.

Charpentier T. (2011) The PAW/GIPAW approach for computing NMR parameters: A new dimension added to NMR study of solids. Solid State NMR 40, 1-20.

Cygan, R.T. and Kubicki, J.D. (2001) Reviews in Mineralogy and Geochemistry: Molecular Modeling Theory: Applications in the Geosciences. 531 p. The Mineralogical Society of America, Washington, D.C. 
Edgar K., Anagnostou E., Pearson P. and Foster G. (2015) Assessing the impact of

570

571

572

573

574

575

576

577

578

579

580

581

582

583

584

585

586

587

588

589

590

591

592

593 diagenesis on 11B, 13C, 180, Sr/Ca and B/Ca values in fossil planktic foraminiferal calcite. Geochim. Cosmochim. Acta 166, 189- 209.

Ferlat G., Cormier L., Mauri F., Balan E., Charpentier T., Anglada E. and Calas G. (2006) $\mathrm{Ab}$ initio calculations on borate systems. Eur. J. Glass Sci. Techno. B 4, 441-444.

Fernández-Díaz L., Fernández-González A. and Prieto M. (2010) The role of sulfate groups in controlling $\mathrm{CaCO}_{3}$ polymorphism. Geochim. Cosmochim. Acta 74, 60646076.

Gabitov R. I., Rollion-Bard C., Tripati A. and Sadekov A. (2014) In situ study of boron partitioning between calcite and fluid at different crystal growth rates. Geochim. Cosmochim. Acta 137, 81-92.

Gaillardet J. and Allègre C.J. (1995) Boron isotopic compositions of corals: Seawater or diagenesis record? Earth Planet. Sci. Lett. 136, 665-676.

Gallet G. A. and Pietrucci F. (2013) Structural cluster analysis of chemical reactions in solution. J. Chem. Phys. 139, 074101.

Garrity K. F., Bennett J. W., Rabe K. M. and Vanderbilt D. (2014) Pseudopotentials for high-throuhput DFT calculations. Comput. Mat. Sci. 81, 446-452.

Giannozzi P., Baroni S., Bonini N., Calandra M., Car R., Cavazzoni C., Ceresoli D., Chiarotti G.L., Cococcioni M., Dabo I., Dal Corso A., de Gironcoli S., Fabris S., Fratesi G., Gebauer R., Gerstmann U., Gougoussis C., Kokalj A., Lazzeri M., Martin-Samos L., Marzari N., Mauri F., Mazzarello R., Paolini S., Pasquarello A., Paulatto L., Sbraccia C., Scandolo S., Sclauzero G., Seitsonen A.P., Smogunov A., Umari P. and Wentzcovitch R.M. (2009) Quantum ESPRESSO: a modular and open-source software project for quantum simulations of materials. J. Phys.: Cond. Matt. 21, 395502. 
594 Gower L. B. (2008) Biomimetic model systems for investigating the amorphous 595 precursor pathway and its role in biomineralization. Chem. Rev. 108, 4551-4627.

596 Henehan M. J., Foster G. L., Rae J. W. B., Prentice K. C., Erez J., Bostock H. C., 597 Marshall B. J. and Wilson P. A. (2015) Evaluating the utility of B/Ca ratios in 598 planktic foraminifera as a proxy for the carbonate system: A case study of 599 Globigerinoides ruber. Geochem. Geophys. Geosyst. 16, 1052-1069

600 Hemming N. G. and Hanson G. N. (1992) Boron isotopic composition and concentration 601 in modern marine carbonates. Geochim. Cosmochim. Acta 56, 537-543.

602 Hemming N. G., Reeder R. J. and Hanson G. N. (1995) Mineral-fluid partitioning and 603 isotopic fractionation of boron in synthetic calcium carbonates. Geochim. 604 Cosmochim. Acta 59, 371-379.

605 Hemming N. G., Reeder R. J. and Hart S. R. (1998) Growth-step-selective incorporation of 606 boron on the calcite surface. Geochim. Cosmochim. Acta 62, 2915-2922.

607 608 609

Hobbs M. Y. and Reardon E. J. (1999) Effect of pH on boron coprecipitation by calcite: Further evidence for nonequilibrium partitioning of trace elements. Geochim. Cosmochim. Acta 63, 1013-1021.

Ishikawa M. and Ichikuni M. (1984) Uptake of sodium and potassium by calcite. Chem. Geol. 42, 137-146

Kaczmarek K., Nehrke G., Misra S., Bijma J. and Elderfield H. (2016) Investigating the effects of growth rate and temperature on the $\mathrm{B} / \mathrm{Ca}$ ratio and $\delta^{11} \mathrm{~B}$ during inorganic calcite formation. Chem. Geol. 421, 81-92.

Kitano Y., Okumura M. and Idogaki (1978) Coprecipitation of borate-born with calcium carbonate. Geochemical Journal 12, 183-189.

Klochko K., Kaufman A. J., Yao W., Byrne R. H. and Tossell J. A. (2006) Experimental measurement of boron isotope fractionation in seawater. Earth Planet. Sci. Lett. 
Laio A. and Parrinello M. (2002) Escaping free-energy minima. Proc. Nat. Acad. Sci. 99, $12562-12566$.

Liu Y. and Tossell J. A. (2005) Ab initio molecular orbital calculations for boron isotope fractionations on boric acids and borates. Geochim. Cosmochim. Acta 69, 39954006.

Lemarchand D., Gaillardet J., Lewin E. and Allègre C. J. (2002) Boron isotope systematics in large rivers: implications for the marine boron budget and paleo-pH reconstruction over the Cenozoic. Nature 408, 951-954.

Martinez-Boti M. A., Marino G., Foster G. L., Ziveri P., Henehan M.J., Rae J. W. B., Mortyn P. G. and Vance D. (2015) Boron isotope evidence for oceanic carbon dioxide leakage during the last deglaciation. Nature 518, 219-222.

Mavromatis V., Montouillout V., Noireaux J., Gaillardet J. and Schott J. (2015) Characterization of boron incorporation and speciation in calcite and aragonite from co-precipitation experiments under controlled $\mathrm{pH}$, temperature and precipitation rate Geochim. Cosmochim. Acta 150, 299-313.

Nir O., Vengosh A., Harkness J. S., Dwyer G. S. and Lahav O. (2015) Direct measurement of the boron isotope fractionation factor: Reducing the uncertainty in reconstructing ocean paleo-pH. Earth Planet. Sci. Lett. 414, 1-5.

Noireaux J., Mavromatis V., Gaillardet J., Schott J., Montouillout V., Louvat P., Rollion-Bard C. and Neuville D. R. (2015) Crystallographic control on the boron isotope paleopH proxy. Earth Planet. Sci. Lett. 430, 398-407.

641 Okumura M. and Kitano Y. (1986) Coprecipitation of alkali metal ions with calcium 642 carbonate. Geochim. Cosmochim. Acta 50, 49-58. 
Pagani M., Lemarchand D., Spivack A and Gaillardet J. (2005) A critical evaluation of the 644 boron isotope-pH proxy: the accuracy of ancient ocean pH estimates. Geochim. 645 Cosmochim. Acta 69, 953-961.

646 Palmer M. R., Pearson P. N. and Cobb S. J. (1998) Reconstructing past ocean pH-depth $647 \quad$ profiles. Science 282, 1468-1471.

648 Pearson P. N. and Palmer M. R. (1999) Middle eocene seawater pH and atmospheric 649 carbon dioxide concentrations. Science 284, 1824-1826.

650 Pearson P. N., Foster G. L. and Wade B. S. (2009) Atmospheric carbon dioxide through 651 the Eocene-Oligocene climate transition. Nature 461, 1110-1113.

652 Perdew J. P., Burke K. and Ernzerhof M. (1996) Generalized gradient approximation 653 made simple. Phys. Rev. Lett. 77, 3865-3868.

654 Pickard C. and Mauri F. (2001) All-electron magnetic response with pseudopotentials: 655 NMR chemical shifts. Phys. Rev. B 63, 245101.

Pietrucci F. and Andreoni W. (2011) Graph theory meets ab initio molecular dynamics: atomic structures and transformations at the nanoscale. Phys. Rev. Lett. 107, 658 085504.

Purgstaller B., Mavromatis V., Immenhauser A. and Dietzel M. (2016) Transformation of 660 Mg bearing amorphous calcium carbonate to Mg-calcite - In situ monitoring. Geochim. Cosmochim. Acta 174, 180-195.

662 Pyykkö P. (2008) Year-2008 nuclear quadrupole moments. Mol. Phys. 106, 1065.

663 Reeder R. J., Lamble G. M., Lee J.-F. and Staudt W. J. (1994) Mechanism of $\mathrm{SeO}_{4}^{2-}$ 664 substitution in calcite: An XAFS study. Geochim. Cosmochim. Acta 58, 5639-5646.

665 Rollion-Bard C., Blamart D., Trebosc J., Tricot G., Mussi A. and Cuif J.-P. (2011) Boron 666 isotops as a pH proxy: A new look at boron speciation in deep-sea corals using ${ }^{11} \mathrm{~B}$ 667 MAS NMR and EELS. Geochim. Cosmochim. Acta 75, 1003-1012. 
668

669

670

671

672

673

674

675

676

677

678

679

680

681

682

683

684

685

686

687

688

689

690

691

Ruiz-Agudo E., Putnis C. V., Kowacz M., Ortega-Huertas M. and Putnis A. (2012) Boron incorporation into calcite during growth: Implications for the use of boron in carbonates as a pH proxy. Earth Planet. Sci. Lett. 345-348, 9-17.

Rustad J. R., Bylaska E. J., Jackson V. E. and Dixon D. A. (2010) Calculation of boronisotope fractionation between $\mathrm{B}(\mathrm{OH})_{3(\mathrm{aq})}$ and $\mathrm{B}(\mathrm{OH})_{4^{-}(\mathrm{aq})}$. Geochim. Cosmochim. Acta 74, 2843-2850.

Sanyal A., Hemming N. G., Hanson G. N. and Broecker W. S. (1995) Evidence for a higher pH in the glacial ocean from boron isotopes in foraminifera. Nature $\mathbf{3 7 3}, 234-236$.

Sen S., Stebbins J. F., Hemming N. G. and Ghosh B. (1994) Coordination environments of B impurities in calcite and aragonite polymorphs: A 11B MAS NMR study. Am. Mineral. 79, 819-825.

Soleilhavoup A., Delaye J.-M., Angeli F., Caurant D. and Charpentier T. (2010) Contribution of first-principles calculations to multinuclear NMR analysis of borosilicate glasses. Magn. Reson. Chem. 48, S159-S170.

Soraru G.D., Babonneau F., Gervais C. and Dallabona N. (2000) Hybrid RSi01:5/ $\mathrm{B}_{2} \mathrm{O}_{3}$ gels from modified silicon alkoxides and boric acid. J. Sol-Gel Sci. and Techno. 18, 11-19.

Spivack A. J., You C. and Smith H. J. (1993) Foraminiferal boron isotope ratios as a proxy for surface ocean pH over the past 21 Myr. Nature 363, 149-151.

Tossell J. A. (2005) Boric acid, "carbonic" acid, and N-containing oxyacids in aqueous solution: Ab initio studies of structure, pKa, NMR shifts, and isotopic fractionations. Geochim. Cosmochim. Acta 69, 5647-5658.

Tossell J. A. (2006) Boric acid adsorption on humic acids: Ab initio calculation of structures, stabilities, ${ }^{11} \mathrm{~B}$ NMR and ${ }^{11} \mathrm{~B},{ }^{10} \mathrm{~B}$ isotopic fractionations of surface complexes. Geochim. Cosmochim. Acta 70, 5089-5103. 
692

693

694

695

696

697

698

699

700

701

702

703

704

705

706

707

708

709

710

711

712

713

714

715

716

Uchikawa J., Penman D. E., Zachos J. C. and Zeebe R. E. (2015) Experimental evidence of kinetic effects on B/Ca in synthetic calcite: Implications for potential $\mathrm{B}(\mathrm{OH})_{4^{-}}$and $\mathrm{B}(\mathrm{OH})_{3}$ incorporation. Geochim. Cosmochim. Acta 150, 171-191.

Vegas A., Cano F. H. and Garcia-Blanco S. (1975) The crystal structure of calcium orthoborate: a redetermination. Acta Crystallogr B 31, 1416-1419.

Vengosh A., Kolodny Y., Starinsky A., Chivas A. R. and McCulloch M. T. (1991) Coprecipitation and isotopic fractionation of boron in modern biogenic carbonates. Geochim. Cosmochim. Acta 55, 2901-2910.

Vielzeuf D., Garrabou J., Baronnet A., Grauby O. and Marschal C. (2008) Nano to macroscale biomineral architecture of red coral (Corallium rubrum). Amer. Mineral. 93, 1799-1815.

Wara M. W., Delaney M. L., Bullen T. D. and Ravelo A. C. (2003) Possible roles of pH, temperature, and partial dissolution in determining boron concentration and isotopic composition in planktonic foraminifera. Paleoceanography 18(4), 1100, doi:10.1029/2002PA000797

Xiao Y. K., Li H. L., Liu W. G., Wang X. F. and Jiang S. Y. (2008) Boron isotopic fractionation in laboratory inorganic carbonate precipitation: Evidence for the incorporation of $\mathrm{B}(\mathrm{OH})_{3}$ into carbonate. Sci. China Ser. D 51, 1776-1785.

Yi H., Balan E., Gervais C., Segalen L., Fayon F., Roche D., Person A., Morin G., Guillaumet M., Blanchard M., Lazzeri M. and Babonneau F. (2013) A carbonate-fluoride defect model for carbonate-rich fluorapatite. Amer. Mineral. 98, 1066-1069.

Zachariasen W. H. (1954) The precise structure of orthoboric acid. Acta Crystallogr. 7, 305-310.

Zeebe R. E. (2005) Stable boron isotope fractionation between dissolved $\mathrm{B}(\mathrm{OH})_{3}$ and $\mathrm{B}(\mathrm{OH})_{4}{ }^{-}$ Geochim. Cosmochim. Acta 69, 2753-2766. 
718 Table 1: Structural and ${ }^{11} \mathrm{~B}$ NMR parameters of boron-bearing calcium carbonate models

\begin{tabular}{|c|c|c|c|c|c|c|c|}
\hline B coordinence & mineral & model & $\begin{array}{l}\text { B-O bond } \\
\text { length }(\AA)\end{array}$ & $\begin{array}{l}\text { O-H bond } \\
\text { length }(\AA)\end{array}$ & $\begin{array}{l}\delta_{\text {iso }} \\
(\mathrm{ppm})\end{array}$ & $\mathrm{C}_{\mathrm{Q}}(\mathrm{MHz})$ & $\eta$ \\
\hline \multirow[t]{12}{*}{ trigonal } & \multirow[t]{4}{*}{ calcite } & $\mathrm{BO}_{3}^{3-}$ & $1.388(\times 3)$ & - & 19.10 & 2.73 & 0.00 \\
\hline & & & 1.345 & - & & & \\
\hline & & $\mathrm{BO}_{2}(\mathrm{OH})^{2-}$ & 1.350 & - & 17.51 & 2.59 & 0.84 \\
\hline & & & $\mathrm{O}(\mathrm{H}) 1.491$ & 0.995 & & & \\
\hline & \multirow[t]{7}{*}{ aragonite } & $\mathrm{BO}_{3}{ }^{3-}$ & $\begin{array}{c}1.380 \\
1383\left(x^{2}\right)\end{array}$ & - & 22.04 & 2.74 & 0.04 \\
\hline & & & 1.343 & - & & & \\
\hline & & $\mathrm{BO}_{2}(\mathrm{OH})^{2-}(\mathrm{A})$ & 1.350 & - & 19.11 & 2.59 & 0.81 \\
\hline & & & $\mathrm{O}(\mathrm{H}) 1.472$ & 0.988 & & & \\
\hline & & & 1.347 & . & & & \\
\hline & & $\mathrm{BO}_{2}(\mathrm{OH})^{2-}(\mathrm{B})$ & 1.349 & - & 18.14 & 2.57 & 0.82 \\
\hline & & & $\mathrm{O}(\mathrm{H}) 1.472$ & 0.991 & & & \\
\hline & takedaite & $\mathrm{BO}_{3}^{3-}$ & 1.391 & - & 22.11 & 2.74 & 0.00 \\
\hline \multirow[t]{24}{*}{ tetragonal } & \multirow[t]{12}{*}{ calcite } & \multirow{4}{*}{$\mathrm{B}(\mathrm{OH})_{4}^{-}$} & O1 1.438 & 1.005 & \multirow[t]{4}{*}{1.05} & \multirow[t]{4}{*}{0.43} & \multirow[t]{4}{*}{0.57} \\
\hline & & & O3 1.477 & 1.002 & & & \\
\hline & & & O4 1.489 & 0.997 & & & \\
\hline & & & O2 1.510 & 0.996 & & & \\
\hline & & \multirow{4}{*}{$\mathrm{BO}(\mathrm{OH})_{3}{ }^{2-}$} & O2 1.402 & - & \multirow[t]{4}{*}{1.29} & \multirow[t]{4}{*}{1.09} & \multirow[t]{4}{*}{0.34} \\
\hline & & & 011.494 & 0.996 & & & \\
\hline & & & O3 1.524 & 0.996 & & & \\
\hline & & & O4 1.532 & 0.994 & & & \\
\hline & & \multirow{4}{*}{$\mathrm{B}(\mathrm{OH})_{4}{ }^{-}, \mathrm{Na}^{+}$} & O1 1.434 & 1.006 & \multirow[t]{4}{*}{1.15} & \multirow[t]{4}{*}{0.56} & \multirow[t]{4}{*}{0.67} \\
\hline & & & O3 1.470 & 0.993 & & & \\
\hline & & & O4 1.499 & 0.997 & & & \\
\hline & & & O2 1.522 & 0.992 & & & \\
\hline & \multirow[t]{12}{*}{ aragonite } & \multirow{4}{*}{$\mathrm{B}(\mathrm{OH})_{4}^{-}$} & O2 1.455 & 0.992 & \multirow[t]{4}{*}{0.81} & \multirow[t]{4}{*}{0.22} & \multirow[t]{4}{*}{0.50} \\
\hline & & & O1 1.476 & 1.008 & & & \\
\hline & & & O4 1.497 & 0.989 & & & \\
\hline & & & O3 1.497 & 1.003 & & & \\
\hline & & \multirow{4}{*}{$\mathrm{BO}(\mathrm{OH})_{3}{ }^{2-}$} & O3 1.402 & - & \multirow[t]{4}{*}{1.02} & \multirow[t]{4}{*}{1.15} & \multirow[t]{4}{*}{0.26} \\
\hline & & & O2 1.492 & 0.987 & & & \\
\hline & & & O1 1.530 & 1.001 & & & \\
\hline & & & O4 1.543 & 0.985 & & & \\
\hline & & \multirow{4}{*}{$\mathrm{B}(\mathrm{OH})_{4}{ }^{-}, \mathrm{Na}^{+}$} & O2 1.457 & 0.990 & 0.88 & 0.38 & 0.58 \\
\hline & & & O1 1.455 & 1.005 & & & \\
\hline & & & O3 1.501 & 0.992 & & & \\
\hline & & & O4 1.514 & 0.989 & & & \\
\hline
\end{tabular}

719

720

721

722 
723 Table 2: Experimental ${ }^{11} \mathrm{~B}$ NMR parameters of synthetic and natural calcium carbonates

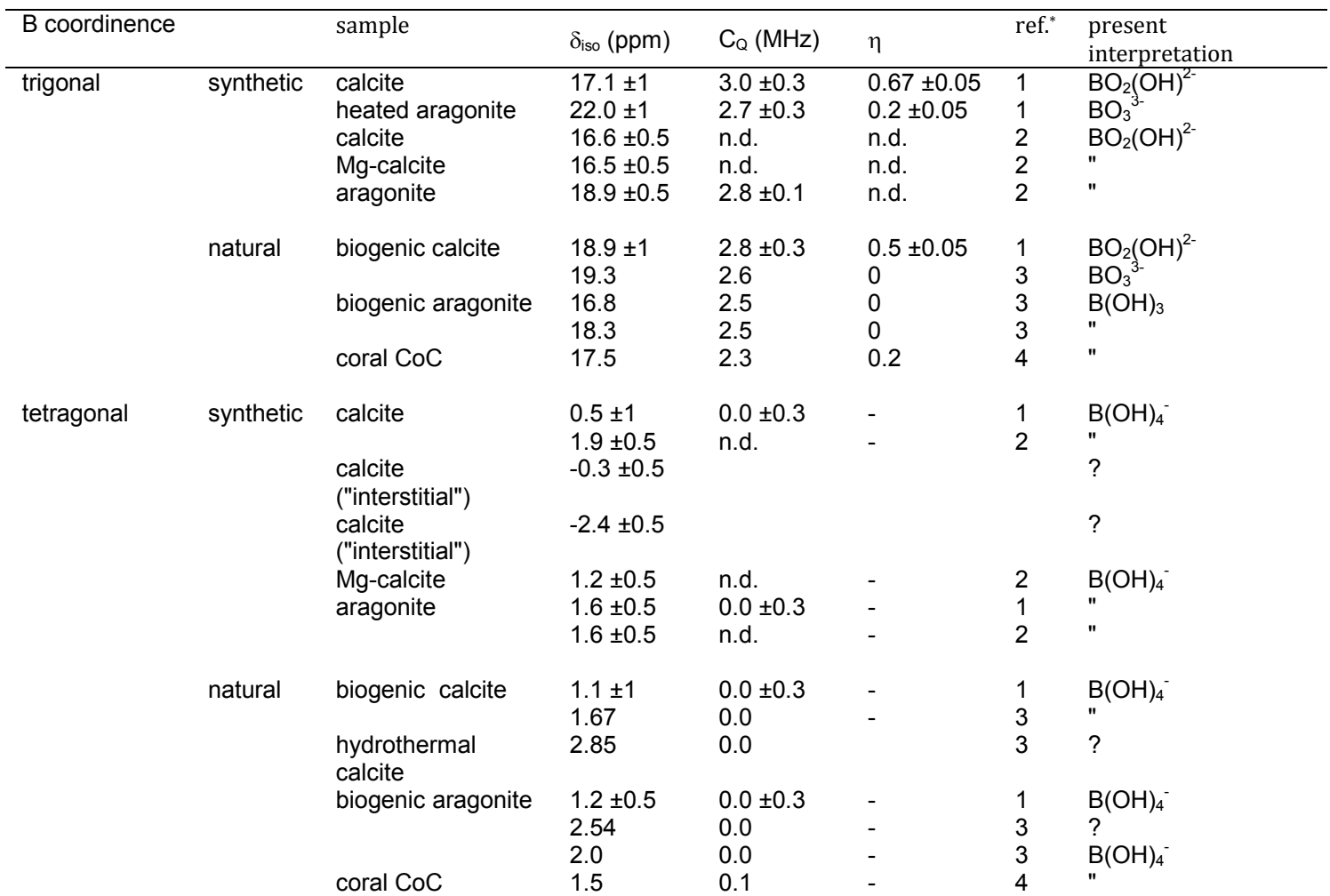

724 "references: ${ }^{1}$ Sen et al. (1994), ${ }^{2}$ Mavromatis et al. (2015), ${ }^{3}$ Klochko et al. (2009), ${ }^{4}$ Rollion-Bard et al. (2011) 


\section{Figure captions}

728

729 Figure 1: Theoretical structure of B-bearing calcite and aragonite obtained from first-

730 principles modeling. The H-bond with an oxygen atom of a neighboring carbonate group

731 is indicated by a dotted line. The star in the tetragonal models indicates the Ca atom

732 closest to boron, which has been selected to test the effect of $\mathrm{Na}^{+}$for $\mathrm{Ca}^{2+}$ substitution.

733 This atom is located at a distance of $3.09 \AA$ and $3.05 \AA$ from the boron atom in calcite and

734 aragonite, respectively.

735 Red: oxygen, blue: calcium, black: hydrogen, purple: carbon, green: boron.

736

737

Figure 2: Summary of first-principles metadynamic run on aragonite. The fluctuations of

738

739

740

741

742

743

744

745

746

747

748

749

750

SPRINT coordinates (top and middle panel) reflect the geometrical changes affecting the H-bonding pattern of $\mathrm{OH}$ groups with $\mathrm{O}$ atoms belonging to surrounding carbonate groups. The bottom panel reports the history dependent bias potential which drives the system away from the previously explored configurations (see text). SPRINT coordinates are defined through the product of the principal eigenvalue of the (real valued) adjacency matrix with its corresponding eigenvector. To enforce invariance under permutation of identical atoms, the resulting values are sorted in ascending order within the oxygen and hydrogen subsets, and are shown with a color gradient ranging from the lowest to the highest components.

Figure 3: Summary of first-principles metadynamic run on calcite. Legend as in Figure 2. 
751 Figure 4: Theoretical and experimental ${ }^{11} \mathrm{~B}$ NMR chemical shifts of trigonal boron. Full 752 symbols: theoretical values from Table 1, open symbols: experimental values from Table 753 2. The circles correspond to nil or weak $\eta$ parameters; whereas the squares correspond 754 to high $\eta$ values indicating in-plane distortion of the trigonal group. The triangles 755 correspond to experimental data for which the $\eta$ parameter is lacking.

756

757 Figure 5: Theoretical and experimental ${ }^{11} \mathrm{~B}$ NMR chemical shifts of tetragonal boron. Full 758 symbols: theoretical values from Table 1, open symbols: experimental values from Table 7592.

760

761

762

763 


\section{calcite}
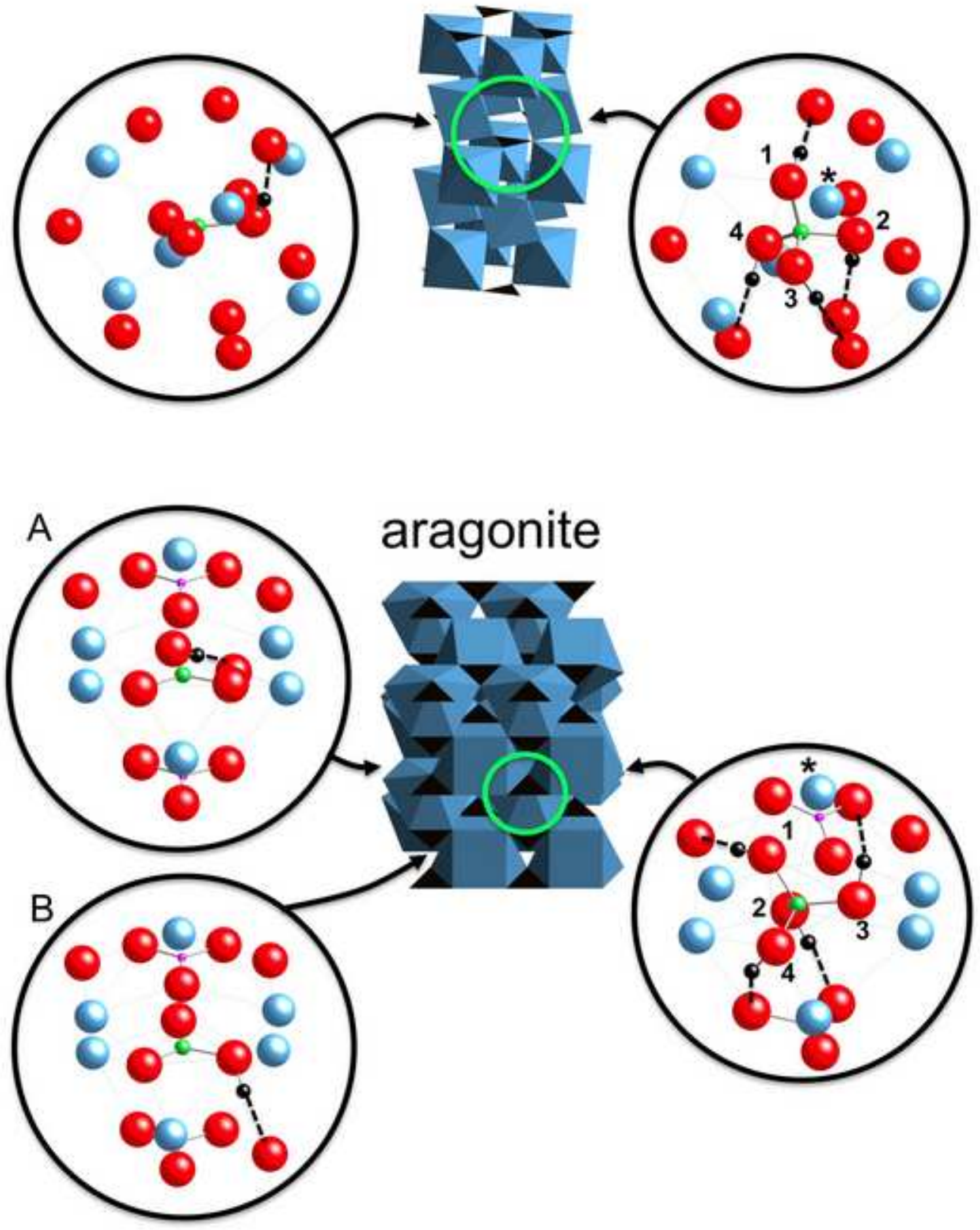
Summary of first-principles metadynamic run on aragonite.

Click here to download high resolution image
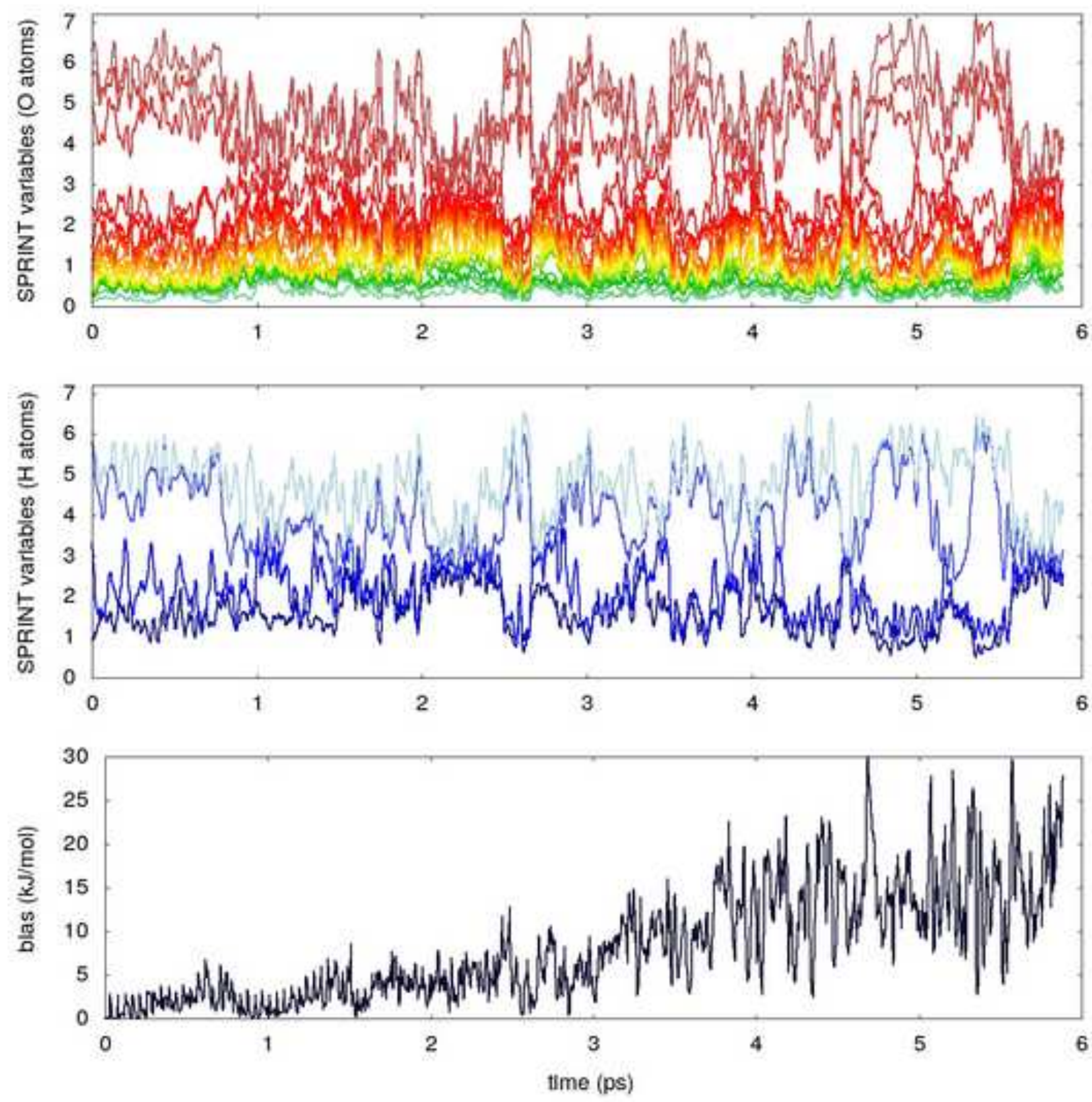
Summary of first-principles metadynamic run on calcite.

Click here to download high resolution image
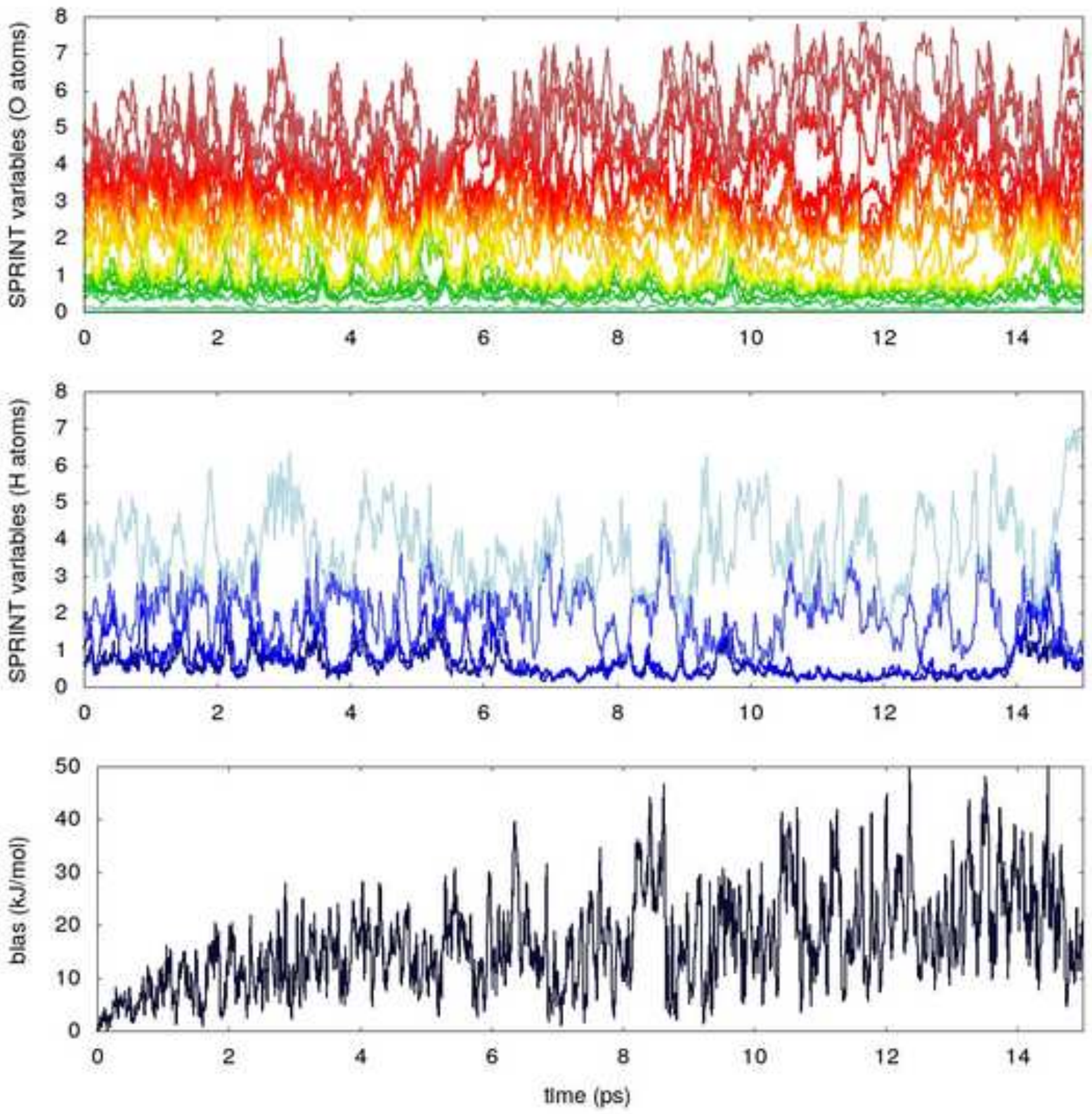


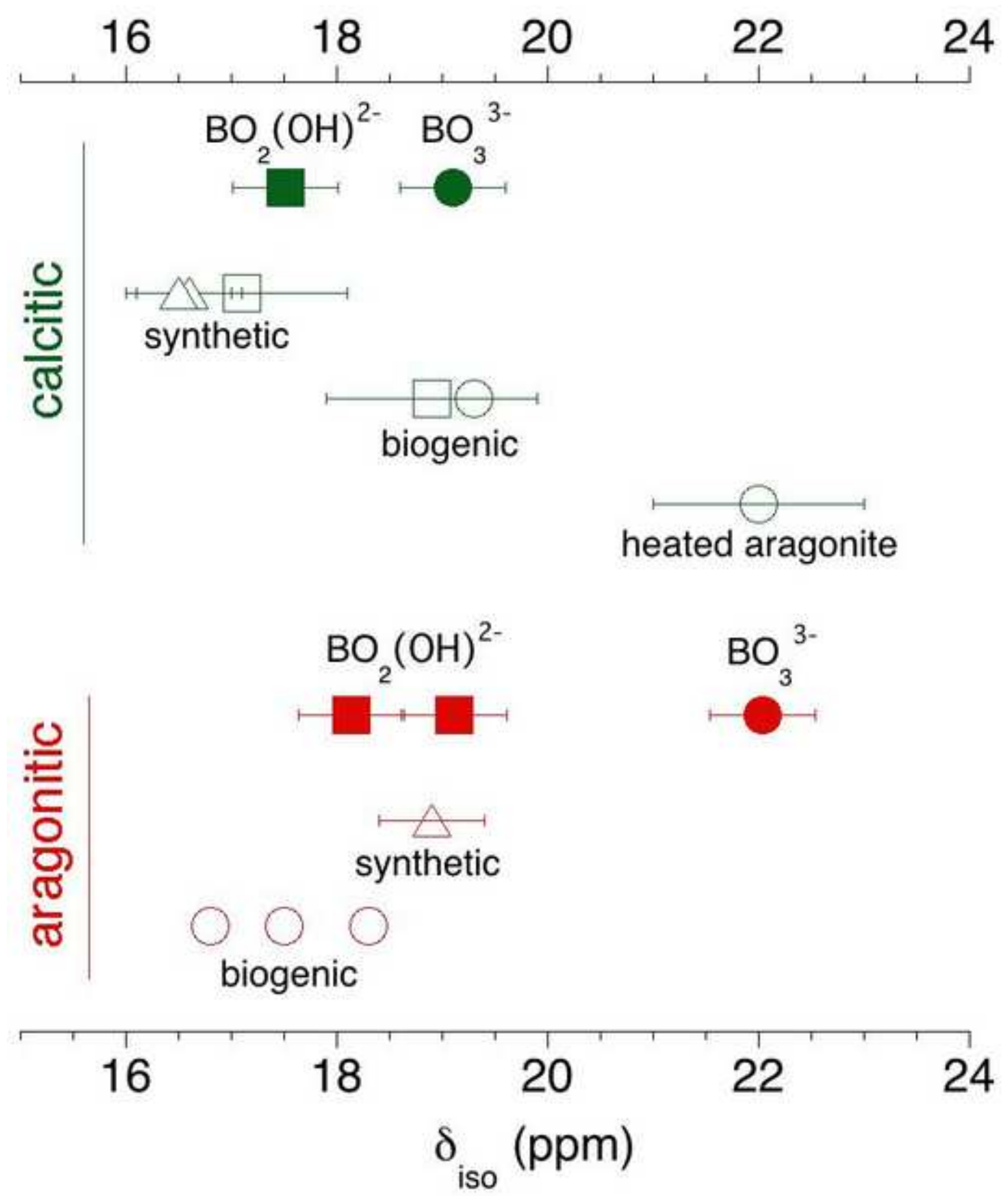




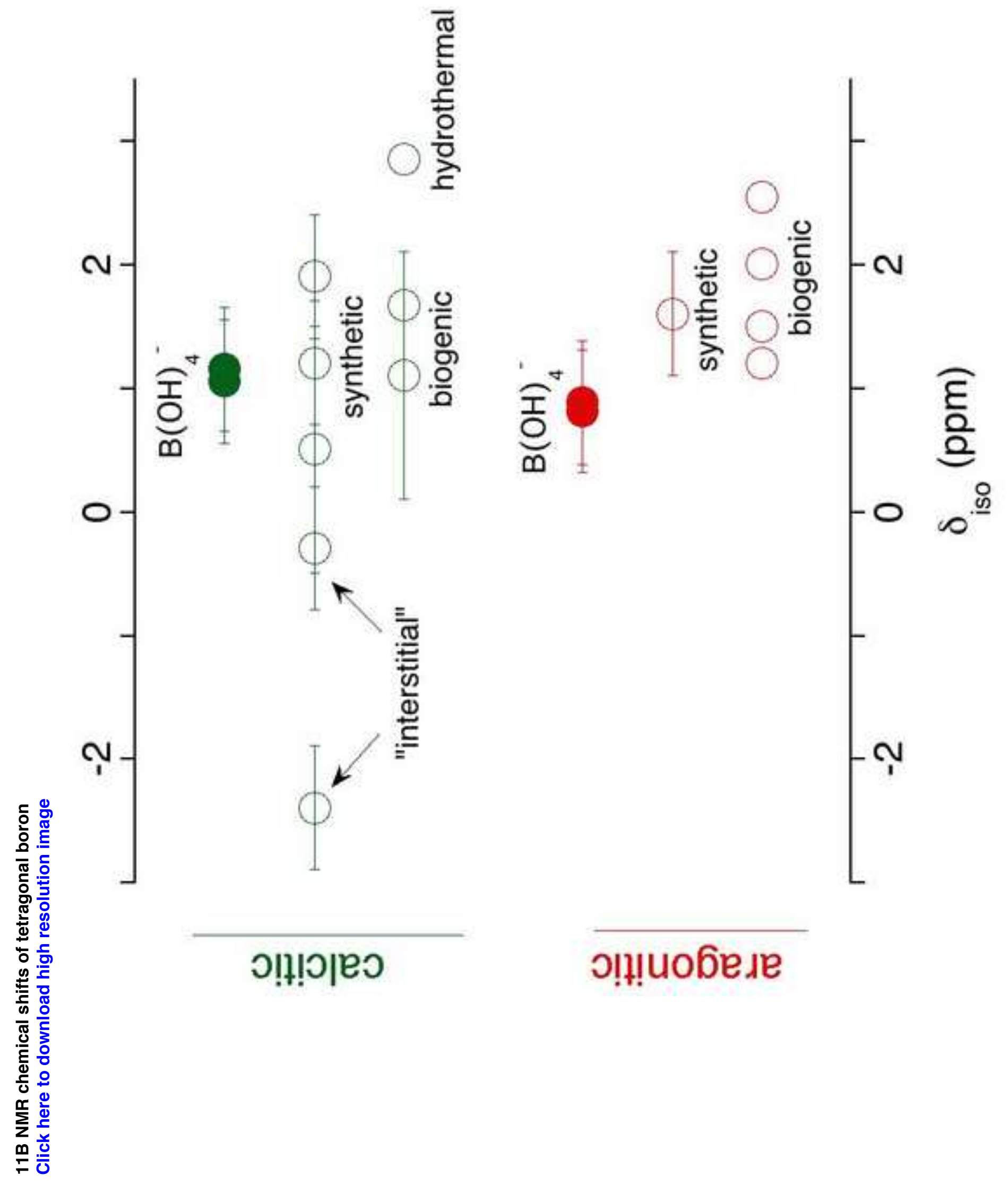

